\title{
CORRESPONDENCE
}

\section{Intolerance: retain healthy scepticism}

The UK government's chief scientist, John Beddington, has done much to promote the potential of science to address pressing global imperatives. But in a straight-talking speech last month, he urged his audience of 300 government scientists to be "grossly intolerant" of "pernicious" and "fatuous" "pseudoscience". In this he included: scepticism of genetic modification technology; "illegitimate" advocacy of environmental precaution in response to unknowns; and suggestions that science is subject to morality. This approach is a rejection not just of irrational denial but of entirely reasonable social scepticism concerning science itself.

It is ironic that defence of scientific rationality is often so emotive. Science does not monopolize social rationality. Although imperfectly realized, the principal distinctions between science and, say religion, politics, commerce or the media are arguably social practices of organized scepticism. Open publication, peer review, experimentation and critical respect for evidence help promote reasoned argument. But rational scepticism is as important outside as inside the social practices of science. Hence the motto of Britain's Royal Society, 'Nullius in verba': take nothing solely on authority even from scientists.

Suppression of rational scepticism of science is also potentially undemocratic. Allocation of research priorities depends on contending interests and values. Technologies are partly shaped by social and political factors, not simply determined by unfolding knowledge. Economic, institutional, military and political pressures help to drive world science in particular directions. The internal dynamics of disciplines and universities are not immune to personality, privilege, prejudice or power. Intrinsic scientific uncertainties underscore the role of democratic debate.

Inhibiting reasonable social questioning of science can foster disingenuity, polarization and untrustworthiness. The progressive social potential of science is therefore supported, not hindered, by greater political tolerance for scepticism.

Andy Stirling University of Sussex, UK.

a.c.stirling@sussex.ac.uk

\section{Intolerance: science informs, not defines}

The UK government's chief scientist, John Beddington, last month demanded intolerance towards the "pseudoscience" used to challenge government science on certain policy issues. However, none of the growing range of public issues involving important scientific questions can be reduced, as Beddington did, simply to "science" or "pseudoscience".

The UK government's scientific advisory apparatus routinely imposes this 'scientism' - to science's own public detriment.

Public disagreement with policy commitments such as genetically modified crops or vaccination of children against measles, mumps and rubella (MMR) is rarely based on opposition to the science itself, even when science is used exclusively to justify policy. People are more likely to object to the brushing aside of their reasonable questions by scientists and policy-makers, and to the exclusion of important factors such as the pervasive exaggeration of scientific understanding and predictive control.

Take the now-discredited claim that the MMR vaccine causes autism: for dissenting parents, the question was whether their child might be at greater individual risk than the average-population risk figures used by the government. This separate question was apparently discounted by government and supporting scientists. Yet which question was more salient was a matter of legitimate difference, not one-dimensional science versus pseudoscience. Both required recognition.

What policy advisers anoint as 'science' for intended public authority always embodies unstated policy-related commitments, including presumptions over the defining questions. Such social questions in public science should be recognized and debated openly. Scientific knowledge should inform public issues, not define them.

Brian Wynne ESRC Centre for Economic and Social Aspects of Genomics (Cesagen), Lancaster University, UK.

b.wynne@lancaster.ac.uk

\section{More protection for China's wetlands}

We estimate that China's natural wetlands are disappearing even faster than feared (Nature 471, 19; 2011). Stricter measures are needed to protect what is left of this valuable ecosystem against the increasing demand for land and development.

Using Landsat Thematic Mapper imagery to map China's wetlands (see, for example, Nature 458,$134 ; 2009$ ), we found that $33 \%$ were lost between 1978 and 2008. Some $55 \%$ of these were natural inland marshes, many of which are biodiversity hotspots. Land reclamation accounted for more than $70 \%$ of the total loss.

The Tibetan plateau generated about 6,000 square kilometres of new wetlands between 1990 and 2008 through deglaciation and thawing of permafrost, reducing wetland losses from 66\% between 1978 and 1990 to just 6\% in 2000-08. Matters are also improving as a result of the Chinese government's substantial efforts in creating new protection areas and initiating wetland restoration projects.

However, more effort is needed to arrest this loss altogether. This should be directed at providing operational support for continuous monitoring of critical wetlands, integrating wetland protection into watershed management plans and specific legislation for wetland protection. Zhenguo Niu, Haiying Zhang State Key Lab of Remote Sensing Science, Institute of Remote Sensing Applications, Beijing, China.

Peng Gong University of California, Berkeley, USA. penggong@berkeley.edu

\section{The social impact of innovation}

David Edgerton wants scientists to be more vocal in opposing hare-brained innovations that stand little or no chance of success (Nature 471, 27-29; 2011).

I agree that we place too high a value on innovation for its own sake, but fail to see what this has to do with Luddism. The objection of the Luddites was not to money being wasted on machines that would not work. On the contrary, the machines that the Luddites tried to destroy worked only too well.

The lesson to be learned from Luddism is both more important and more sophisticated: when evaluating the worth of an innovation, we should be concerned with its wider social implications, as well as its narrowly economic ones. In other words, scientists should have consciences.

Timothy Roper University of Sussex, UK.

t.j.roper@sussex.ac.uk 